\title{
Differential effects of natural palm oil, chemically- and enzymatically-modified palm oil on weight gain, blood lipid metabolites and fat deposition in a pediatric pig model
}

Eric N Ponnampalam ${ }^{1 *}$, Paul Lewandowski ${ }^{2}$, Kalanithi Nesaratnam ${ }^{3}$, Frank R Dunshea ${ }^{4}$ and Harsharn Gill ${ }^{1}$

\begin{abstract}
Background: Increasing prevalence of obesity and overweight in the Western world, continue to be a major health threat and is responsible for increased health care costs. Dietary intervention studies show a strong positive association between saturated fat intake and the development of obesity and cardiovascular disease. This study investigated the effect of positional distribution of palmitic acid (Sn-1, 2 \& 3) of palm oil on cardiovascular health and development of obesity, using weaner pigs as a model for young children.
\end{abstract}

Methods: Male and female weaner piglets were randomly allocated to 4 dietary treatment groups: 1) pork lard (LRD); 2) natural palm olein (NPO); 3) chemically inter-esterified $\mathrm{PO}(\mathrm{CPO})$ and 4) enzymatically inter-esterified $\mathrm{PO}(\mathrm{EnPO})$ as the fat source. Diets were formulated with $11 \%$ lard or with palm olein in order to provide $31 \%$ of digestible energy from fat in the diet and were balanced for cholesterol, protein and energy across treatments.

Results: From 8 weeks onwards, pigs on EnPO diet gained $(P<0.05)$ more weight than all other groups. Feed conversion efficiency (feed to gain) over the 12 week experimental period did not vary between treatment groups. Plasma LDL-C content and LDL-C/HDL-C ratio in pigs fed natural PO tended to be lower compared to all other diets. The natural $P O$ lowered $(P<0.02)$ the plasma triglyceride $(T G)$ content relative to the lard or EnPO diets, but was not different from the CPO diet. The natural PO diet was associated with lower $(P<0.05)$ saturated fat levels in subcutaneous adipose tissue than the CPO and EnPO diets that had lower saturated fat levels than the lard diet. Female pigs had lower lean and higher fat and fat:lean ratio in the body compared with male pigs. No difference in weight gain or blood lipid parameters was observed between sexes.

Conclusions: The observations on plasma TG, muscle and adipose tissue saturated fatty acid contents and back fat (subcutaneous) thickness suggest that natural palm oil may reduce deposition of body fat. In addition, dietary supplementation with natural palm oil containing palmitic acid at different positions in meat producing animals may lead to the production of meat and meat products with lower saturated fats. An increase in fat content and a decrease in lean content in female pigs resulted in an increased body fat:lean ratio but gender had no effect on blood lipid parameters or insulin concentrations.

\footnotetext{
* Correspondence: eric.ponnampalam@dpi.vic.gov.au

'AgriFood Production Systems, FFSR, Department of Primary Industries, 600

Sneydes Road, Werribee VIC 3030, Australia

Full list of author information is available at the end of the article
} 


\section{Background}

Increasing prevalence of obesity and overweight in the Western world, continue to be a major health threat and is responsible for increased health care costs $[1,2]$. High blood cholesterol, particularly low density lipoprotein cholesterol (LDL-C), high blood triglycerides (TG) and high blood glucose are major risk factors leading to the development of diseases such as cardiovascular disease (CVD), obesity and diabetes. Dietary intervention studies indicate a strong positive association between saturated fat intake and the development of obesity and CVD [3-5]. Due to this reason, there has been recommendation to replace saturated fats with unsaturated fats [6-8].

Among saturated fats, myristic (14:0), palmitic (16:0) and lauric (12:0) has been reported to be detrimental to health compared with the shorter chain (4:0 - 10:0) saturated fats [3] and unsaturated fatty acid such as oleic acid [9]. There is a considerable body of published work on the type of fatty acids (polyunsaturated vs monounsaturated vs saturated fats) and their association with disease development or prevention. Research shows that the fatty acid composition of dietary fats present in TGs mainly affects the development of obesity, diabetes and hyperlipidemia [5,10-12]. The structure of TG has been reported to be a factor affecting digestion and nutritional behaviour of lipids $[4,13,14]$. To date, little research has focused on understanding how the position of saturated fats within the TG molecule affects cholesterol metabolism and fat accretion.

Changes in risk factors or impairment in metabolic function due to dietary habits in early life may lead to serious metabolic disorders later in life. For example, high intake of saturated fats in early childhood may lead to changes in lipid metabolism that promotes the development of atherosclerosis in adulthood [15]. The digestion of fats by gastric and pancreatic lipases hydrolyses fatty acids from Sn-1 \& 3 positions of TGs and generates free fatty acids and 2-monoglycerides [16]. Studies have shown that the absorption of palmitic acid is lower when a greater proportion of dietary palmitic acid occurs at $\mathrm{Sn}-1$ \& -3 than the $\mathrm{Sn}-2$ position [13]. Palm olein $(\mathrm{PO})$, the liquid fraction of palm oil, contains $\sim 70 \%$ oleic acid $(18: 1)$ and $12 \%$ palmitic acid (16:0) occurring at $\mathrm{Sn}$-2, i.e., most of the palmitic acid occurs at $\mathrm{Sn}-1$ \& -3 positions. As a result, the level of palmitic acid in the circulation of people consuming palm oil would be expected to be lower, which may result in lower blood cholesterol and tissue TG levels. However, this effect remains to be demonstrated experimentally. This study investigated the effect of positional distribution of palmitic acid in palm oil on blood lipids and fat deposition in the development of obesity, using young pigs as a model for children.

\begin{tabular}{|c|c|c|c|c|}
\hline Ingredient & Lard & NPO & CPO & EnPo \\
\hline Wheat & 42.06 & 42.06 & 42.06 & 42.06 \\
\hline Barley & 15.00 & 15.00 & 15.00 & 15.00 \\
\hline Soybean meal & 18.18 & 18.18 & 18.18 & 18.18 \\
\hline Meat meal & 10.00 & 10.00 & 10.00 & 10.00 \\
\hline Blood meal & 2.00 & 2.00 & 2.00 & 2.00 \\
\hline Dicalcium phosphate & 0.54 & 0.54 & 0.54 & 0.54 \\
\hline Limestone & 0.53 & 0.53 & 0.53 & 0.53 \\
\hline Salt & 0.20 & 0.20 & 0.20 & 0.20 \\
\hline Vitamin-Mineral Premix & 0.20 & 0.20 & 0.20 & 0.20 \\
\hline Lysine & 0.14 & 0.14 & 0.14 & 0.14 \\
\hline Threonine & 0.15 & 0.15 & 0.15 & 0.15 \\
\hline Tylan & 0.08 & 0.08 & 0.08 & 0.08 \\
\hline Test Oil & - & 11.0 & 11.0 & 11.0 \\
\hline Lard & 11.0 & & & \\
\hline Cholesterol & - & 0.1 & 0.1 & 0.1 \\
\hline
\end{tabular}

Values are expressed as $\mathrm{g} / 100 \mathrm{~g}$ diet (\%) on air dry basis.

\section{Materials and methods}

Forty weaner piglets (Large White X Landrace; 20 males and 20 females) weighing $6.38 \pm 0.1 \mathrm{~kg}$ (Mean $\pm \mathrm{SE}$ ) were randomly allocated to one of four dietary treatments: 1) pork lard; 2) natural palm olein (NPO); 3) chemically inter-esterified PO (CPO); 4) enzymatically inter-esterified PO (EnPO) as the fat source (Table 1). The chemical modification provided altered levels of oleic acid at $\mathrm{Sn}$-2, whereas enzymatic modification provided altered levels of palmitic acid at Sn-1 \& Sn-3 positions [17]. Diets were formulated with $11 \%$ of lard or with palm oil (palm olein) in order to provide $16.0 \mathrm{MJ} /$ $\mathrm{kg}$ digestible energy, $13.4 \%$ total fat and $31 \%$ of digestible energy from fat. Diets were balanced for cholesterol, protein and energy across treatments (Table 1). Following one week of adaptation on a commercial weaner ration, feed intake and body weights were recorded at 14 day intervals. Fasting blood samples were collected on days 0 (before commencement), 28, 56 \& 84. Two replicates were conducted seven weeks apart. The study protocol was approved by the Animal Ethics Committee of the Department of Primary Industries, Victorian Government.

\section{Sample collection}

At the end of feeding period, animals were slaughtered humanely at a commercial abattoir. Back fat depth (P2) was measured at $12^{\text {th }}$ rib, $65 \mathrm{~mm}$ away from the midline (spinal cord), which is a standard measure to assess the carcass fat content. Carcass fatness was assessed after the removal of visceral components and some pelvic and kidney fat tissues if present in excess level as a 
standard for commercial procedure. The left side of each carcass was transported by a refrigerated truck to the Meat Research and Training Centre, Werribee, Victoria for sampling of muscle and adipose tissue and measurement of body composition. Muscle (50 g) and fat (20 g) tissues were collected from longissimus lumborum site (i.e., loin muscle area above $13^{\text {th }}$ rib). Half carcasses (left sides) were weighed and the composition of each half carcass was determined using a Hologic QDR4500 dual energy X-ray absorptiometry (DXA) machine, using a calibration equation [18]. Weights of lean tissue, fat tissue, bone mineral content and total carcass weight were calculated for each carcass using the calibration equation and converted to percentages of total carcass weight as described in Ponnampalam et al. [19].

\section{Plasma lipids}

Blood was transported to the laboratory on ice packs within 2 hours of collection and then centrifuged at 3000 g for 10 minutes. Plasma was then collected into aliquots and frozen at $-80^{\circ} \mathrm{C}$ for further analysis of total cholesterol, high-density lipoprotein cholesterol (HDL-C), low-density lipoprotein cholesterol (LDL-C), triglycerides (TG), insulin and glucose. Total plasma cholesterol, HDL-C, and plasma TGs were determined via the use of colorimetric kits (Thermo Electron, Sydney, Australia) in accordance with the manufacturer's instructions. Low density lipoprotein cholesterol (LDL-C) was determined using the Friedewald equation [20]: LDL-C = Total Cholesterol - HDL-C - (TG/5). Plasma insulin was measured using a porcine insulin RIA Kit (Linco Research, St. Charles, MO) in accordance with the manufacturer's instructions.

\section{Fatty acid determination in muscle and adipose tissue}

Lipid extractions and fatty acid analyses of meat samples were carried out in duplicate. Seven gram portions of minced homogenized muscle or 0.5 gram of fat (subcutaneous adipose) tissue were extracted with $60 \mathrm{~mL}$ of chloroform-methanol $(2: 1 \mathrm{v} / \mathrm{v})$ containing $10 \mathrm{mg} / \mathrm{L}$ of butylated hydroxytoluene and $5 \mathrm{mg}$ of methyl tricosanoate as internal standard (C23:0, Nu-Chek-Prep, Ely-sian, MN, USA). Following extraction overnight and filtering, $8 \mathrm{~mL}$ aliquot of the filtrate was mixed with $2 \mathrm{~mL}$ of $0.9 \% \mathrm{NaCl}$, shaken and left overnight at $4{ }^{\circ} \mathrm{C}$ to remove aqueous impurities. On the following day, the lower phase containing lipids was evaporated with pure nitrogen gas and fatty acids methyl esters (FAME) of the total lipids were prepared by the addition of $1 \mathrm{~mL}$ of toluene and $3 \mathrm{~mL}$ of $0.9 \mathrm{M} \mathrm{H}_{2} \mathrm{SO}_{4}$ in methanol and heating the resulting solution at $70^{\circ} \mathrm{C}$ for $2 \mathrm{~h}$ with shaking at $15 \mathrm{~min}$ intervals.

Upon cooling, $3 \mathrm{~mL}$ of petroleum ether and $3 \mathrm{~mL}$ of distilled water was added. This mixture was then thoroughly mixed and centrifuged for $10 \mathrm{~min}$ at $1000 \mathrm{rpm}$.
The fatty acid containing upper phase was separated in a screw-capped tube, evaporated to dryness and reconstituted with petroleum ether. The fatty acid methyl esters were separated by capillary gas liquid chromatography using a $60 \mathrm{~m} \times 0.32 \mathrm{~mm}$ fused silica bonded phase column (BPX70, SGE, Melbourne, Australia). Fatty acids were identified by comparison with standard mixtures of FAME (Nu-Chek-Prep, Elysian, MN, USA), and the results were calculated using response factors derived from chromatograph standards of known composition as determined previously [21].

\section{Statistical analysis}

Data were subjected to Analysis of Variance (ANOVA) using Genstat version 10.1. Data collected from all 40 animals on feed intake, growth, weight gain, FCR, carcass fatness and blood lipid profiles were analysed for the main effect of dietary treatments and sexes. The means of treatment groups and sexes for blood lipids and insulin were analysed using ANOVA with initial concentrations, at day 0 , as covariates. For the determination of carcass composition as fat, lean (muscle) and bone mineral (ash) percentages or weights (mass), carcass weight was used as a covariate. Means were compared using least significant differences (LSD) and $\mathrm{P}<0.05$ was considered statistically significant.

\section{Results}

Feed intake, growth, weight gain and gain $/ \mathrm{Kg}$ feed consumption of animals

Animals on EnPO diet consumed 14-15 kg more feed $(\mathrm{P}<0.05$. Table 2$)$ over the 12 week period compared with other treatments. As a consequence, there was a greater increase in body weight $(\mathrm{P}<0.001$; Table 2$)$ and weight gain $(\mathrm{P}<0.001$; Table 2$)$ in EnPO animals after the 12 weeks of feeding compared with lard, NPO and CPO. Weight gain per kilogram feed consumed (FCR) was similar between all treatments, ranging from $0.49-0.51 \mathrm{~kg}$ gain $/ \mathrm{kg}$ of feed consumed (Table 2). Weekly body weight records further indicated that animals consuming diets supplemented with EnPO gained significantly more weights from 8 weeks onwards than the other groups $(P<0.05$, Figure 1$)$. There were no differences between sexes in feed intake, weight gain and gain per $\mathrm{kg}$ feed intake (Table 2).

\section{Carcass fatness}

Body fatness evaluated by back fat measurement at the P2 site (a measure of external adipose tissue thickness) was lower $(\mathrm{P}<0.05)$ in NPO animals compared with lard fed animals, but CPO and EnPO were not different from NPO or lard treatments (Table 2). Carcass composition assessed by DXA showed no differences in carcass percentages (fatness, muscle content and bone content) 
Table 2 Feed intake, final liveweight, weight gain, gain per feed, carcass weight, back fat depth and carcass composition as weights (mass) or percentages (\%) of pigs after 12 weeks of feeding lard, natural palm oil (NPO), chemically modified palm oil (CPO) and enzymatically modified palm oil (EnPO) diets*

\begin{tabular}{|c|c|c|c|c|c|c|c|c|}
\hline & Lard & NPO & $\mathrm{CPO}$ & EnPO & Female & Male & SEM Diet & SEM Sex \\
\hline Feed intake (Kg) & $116.4^{a}$ & $117.2^{a}$ & $117.3^{a}$ & $131.1^{b}$ & 120.3 & 120.7 & 4.46 & 2.65 \\
\hline Final liveweight & $65.0^{\mathrm{a}}$ & $66.3^{\mathrm{a}}$ & $66.9^{a}$ & $70.4^{b}$ & 66.2 & 68.1 & 1.75 & 3.23 \\
\hline Weight gain (Kg) & $58.6^{a}$ & $59.9^{\mathrm{a}}$ & $60.5^{a}$ & $64.1^{b}$ & 59.7 & 61.9 & 1.72 & 2.93 \\
\hline Gain/feed & 0.50 & 0.51 & 0.51 & 0.50 & 0.50 & 0.52 & 0.02 & 0.02 \\
\hline Carcass weight (kg) & 52.5 & 52.5 & 53.2 & 53.5 & 52.7 & 53.1 & 1.46 & 0.97 \\
\hline Back fat depth (mm) & $13.2^{b}$ & $11.2^{\mathrm{a}}$ & $12.6^{\mathrm{ab}}$ & $12.3^{a b}$ & 12.09 & 12.56 & 0.82 & 0.90 \\
\hline Half carcass fat (kg) & 4.92 & 4.78 & 4.95 & 4.77 & $5.09^{x}$ & $4.62^{y}$ & 0.31 & 0.15 \\
\hline Half carcass lean (kg) & 17.59 & 17.74 & 17.53 & 17.63 & $17.39^{x}$ & $17.86^{y}$ & 0.29 & 0.14 \\
\hline Half carcass bone (ash, kg) & 0.70 & 0.69 & 0.69 & 0.70 & 0.70 & 70 & 0.01 & 0.01 \\
\hline Fat (\%) & 21.2 & 20.5 & 21.5 & 20.8 & $21.9^{x}$ & $19.9^{y}$ & 0.93 & 0.76 \\
\hline Lean (\%) & 75.9 & 76.6 & 75.6 & 76.3 & $75.1^{x}$ & $77.1^{\mathrm{y}}$ & 0.86 & 0.62 \\
\hline Ash (\%) & 3.03 & 3.02 & 3.03 & 3.02 & 3.02 & 3.03 & 0.03 & 0.01 \\
\hline Fat:lean ratio & 0.28 & 0.27 & 0.29 & 0.27 & $0.29^{x}$ & $0.26^{y}$ & 0.02 & 0.01 \\
\hline
\end{tabular}

"Means are average of 10 observations for treatments and 20 observations for sexes. Data were presented as mean \pm SEM.

$a, b, c \& x, y$ Means with different superscripts between dietary treatments and sexes, respectively differ significantly at $P<0.05$.

or by weights (mass) between treatment groups (Table 2). Females had lower body lean content $(\mathrm{P}<0.01)$, higher fat content $(\mathrm{P}<0.02)$ and higher fat:lean ratio $(\mathrm{P}<0.02)$ than male pigs.

\section{Blood lipid profiles}

There was no difference in total cholesterol, LDL-C or HDL-C or insulin levels between treatments after 12 weeks of feeding (Table 3). Blood TG levels were lower in animals fed NPO diet compared to lard and EnPO $(\mathrm{P}<0.02$, Table 3$)$. There were no differences in the concentrations of cholesterol, TG, LDL-C, HDL-C or insulin between males and females (Table 3).

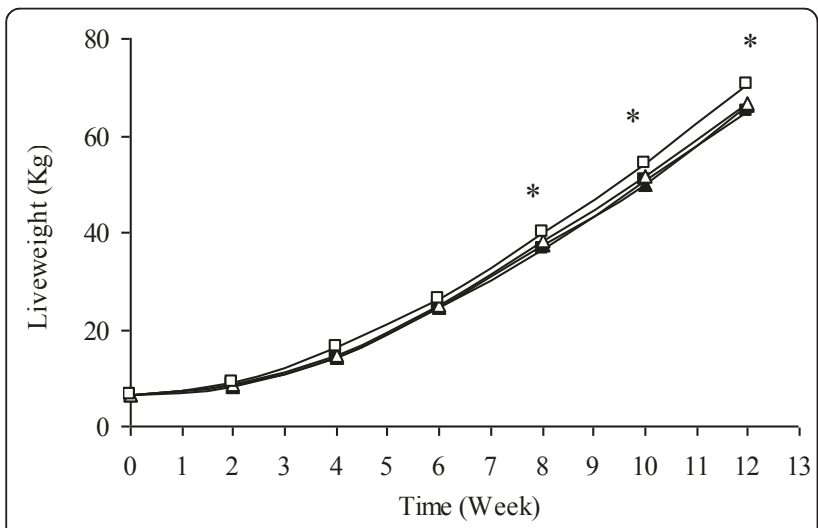

Figure 1 Mean live weight of animals over the 12 week feeding period. Data is presented as mean across all treatment for 12 weeks of feeding period. *Indicates that EnPO (opened square) gained significantly more weight from 8 weeks onwards compared with lard (closed black square), NPO (closed black triangle) and CPO (opened triangle) groups $(\mathrm{P}<0.05)$.
Muscle and adipose tissue fatty acid composition

Myristic acid (14:0) and stearic acid (18:0) content in muscle from all palm oil fed pigs was significantly lower than lard fed pigs $(\mathrm{P}<0.01$, Table 4$)$. Similarly, muscle palmitoleic acid (16:1) content was also significantly lower in all palm oil fed pigs compared to lard fed pigs $(\mathrm{P}<0.01$, Table 4$)$, with NPO and CPO fed pigs displaying lower palmitoleic acid levels than EnPO fed pigs. Adipose tissue total saturated fatty acid content from all palm oil fed pigs was significantly lower than lard fed pigs $(\mathrm{P}<0.05$, Table 5$)$, with NPO fed pigs displaying lower total saturated fatty acid levels than $\mathrm{CPO}$ and EnPO fed pigs. Similarly, adipose tissue myristic acid (14:0) content was also significantly lower in all palm oil fed pigs compared to lard fed pigs $(\mathrm{P}<0.03$, Table 5$)$, with NPO and CPO fed pigs displaying lower myristic acid levels than EnPO fed pigs.

In the muscles, females had greater $(\mathrm{P}<0.05)$ levels of 14:0, 16:0, 18:1 than male pigs. Total PUFA was higher $(\mathrm{P}<0.02)$ in males while total monounsaturated fats were higher $(\mathrm{P}<0.02)$ in females (Table 4$)$. In adipose tissues, there were no differences in fatty acids between males and females (Table 5). There was no significant diet $\mathrm{x}$ sex interactions for feed consumption, weight gain, blood or muscle and adipose tissues.

\section{Discussion}

Performance of animals and fatness in the body

Feed intake data shows that pigs on EnPO diet gained significantly more weight than all other groups. However this did not influence the feed to gain ratio (feed conversion efficiency), fat deposition or fat:lean ratio in the body over the whole experimental period. Body fatness evaluated by back fat measures indicated that the 
Table 3 Blood total cholesterol, LDL-cholesterol (LDL-C), HDL-cholesterol (HDL-C), ratio of LDL-C/HDL-C, triglycerides (TG) and plasma insulin concentrations of pigs at week 12 of feeding lard, natural palm oil (NPO), chemically modified palm oil (CPO) and enzymatically modified palm oil (EnPO) diets*

\begin{tabular}{|c|c|c|c|c|c|c|c|c|}
\hline & Lard & NPO & CPO & EnPO & Female & Male & SEM Diet & SEM Sex \\
\hline Cholesterol (mmol/L) & 3.38 & 3.37 & 3.57 & 3.56 & 3.90 & 3.04 & 0.77 & 0.74 \\
\hline $\mathrm{LDL}-\mathrm{C}(\mathrm{mmol} / \mathrm{L})$ & 1.87 & 1.69 & 2.00 & 2.04 & 2.25 & 1.55 & 0.64 & 0.50 \\
\hline $\mathrm{HDL}-\mathrm{C}(\mathrm{mmol} / \mathrm{L})$ & 1.51 & 1.68 & 1.57 & 1.52 & 1.59 & 1.55 & 0.19 & 0.22 \\
\hline LDL-C:HDL-C ratio & 1.21 & 1.17 & 1.38 & 1.44 & 1.58 & 1.03 & 0.29 & 0.44 \\
\hline Triglycerides (mmol/L) & $0.49^{b}$ & $0.30^{a}$ & $0.39^{\mathrm{ab}}$ & $0.64^{b}$ & 0.41 & 0.50 & 0.11 & 0.14 \\
\hline Insulin ( $\mu \mathrm{U} / \mathrm{ml})$ & 3.40 & 3.09 & 4.15 & 4.57 & 3.28 & 4.33 & 1.18 & 0.91 \\
\hline
\end{tabular}

Initial concentrations were used as covariates for the analysis.

*Means are average of 10 observations for treatments and 20 observations for sexes. Data presented as mean \pm SEM.

$\mathrm{a}, \mathrm{b}, \mathrm{c}$ Means with different superscripts between dietary treatments differ significantly at $\mathrm{P}<0.05$.

NPO diet significantly lowered subcutaneous adipose tissue deposition (external fat deposition) compared with the lard diet. These observations are consistent with the findings of [22] who reported similar increases in feed intake and weight gain. In contrast however, these researchers found increases in back fat thickness rather than a reduction. However there was no effect of other palm oil diets (CPO \& EnPO) compared to NPO or lard diets. The reduction in adipose tissue thickness with NPO was not evident from carcass fatness, as determined by DXA, although NPO fed animals had a slightly lower percent fat than the other treatment groups. Muscle and bone mineral contents (\%) determined by DXA showed similar levels between dietary groups. Although feed consumption and weight gain were not affected by sex, females had greater fatness

Table 4 Fatty acid composition (\%) of muscle longissimus of pigs after 12 weeks of feeding lard, natural palm oil (NPO), chemically modified palm oil (CPO) and enzymatically modified palm oil (EnPO) diets*

\begin{tabular}{lllllllll}
\hline & Lard & NPO & CPO & EnPO & Female & Male & $\begin{array}{l}\text { SEM } \\
\text { Diet }\end{array}$ & $\begin{array}{l}\text { SEM } \\
\text { Sex }\end{array}$ \\
\hline $12: 0$ & 0.06 & 0.06 & 0.06 & 0.06 & 0.06 & 0.06 & 0.004 & 0.002 \\
$14: 0$ & $1.12^{\mathrm{b}}$ & $0.95^{\mathrm{a}}$ & $0.92^{\mathrm{a}}$ & $0.96^{\mathrm{a}}$ & $1.1^{\mathrm{x}}$ & $0.95^{\mathrm{y}}$ & 0.06 & 0.028 \\
$16: 0$ & 24.5 & 24.9 & 25.3 & 25.0 & $25.2^{\mathrm{x}}$ & $24.7^{\mathrm{y}}$ & 0.41 & 0.21 \\
$16: 1$ & $2.79^{\mathrm{b}}$ & $2.35^{\mathrm{a}}$ & $2.26^{\mathrm{a}}$ & $2.47^{\mathrm{ab}}$ & $2.59^{\mathrm{x}}$ & $2.35^{\mathrm{y}}$ & 0.17 & 0.09 \\
$18: 0$ & $11.6^{\mathrm{b}}$ & $10.5^{\mathrm{a}}$ & $10.9^{\mathrm{a}}$ & $10.5^{\mathrm{a}}$ & 10.9 & 10.8 & 0.30 & 0.27 \\
$18: 1$ & 43.2 & 44.5 & 42.3 & 43.7 & $44.1^{\mathrm{x}}$ & $42.7^{\mathrm{y}}$ & 1.51 & 0.53 \\
$18: 2$ & 14.5 & 14.7 & 16.1 & 15.2 & $14.1^{\mathrm{x}}$ & $16.2^{\mathrm{y}}$ & 1.38 & 0.70 \\
Total SFA & 37.9 & 36.9 & 37.7 & 37.1 & 37.8 & 37.1 & 0.67 & 0.44 \\
Total & 46.0 & 46.9 & 44.5 & 46.1 & $46.7^{\mathrm{x}}$ & $45.1^{y}$ & 1.61 & 0.52 \\
MUFA & & & & & & & & \\
Total & 16.1 & 16.2 & 17.7 & 16.7 & $15.6^{\mathrm{x}}$ & $17.8^{\mathrm{y}}$ & 1.51 & 0.74 \\
PUFA & & & & & & & &
\end{tabular}

${ }^{*}$ Means are average of 10 observations for treatments and 20 observations for sexes. Data presented as mean \pm SEM.

$a, b, c \& x, y$ Means with different superscripts between dietary treatments and sexes, respectively differ significantly at $\mathrm{P}<0.05$.

Abbreviations: SFA, saturated fatty acids; MUFA, monounsaturated fatty acids; PUFA, polyunsaturated fatty acids. and fat:lean ratio compared to males, suggesting that dietary energy was diverted to fat deposition in females. This could be due to fundamental differences between males and females in the development of lean and fat mass in the body. Young females (18-20 years) have been reported to have significantly higher fat body mass by weight and \% fat body mass compared with their male counterparts, which is similar to the findings in the present study [23].

Plasma metabolites and fatty acid content in muscle and adipose tissue

Heart disease is one of the leading causes of mortality in the Western world. Due to the link between obesity and heart disease, prevention of heart disease through

Table 5 Fatty acid composition (\%) of subcutaneous fat (adipose) tissue of pigs after 12 weeks of feeding lard, natural palm oil (NPO), chemically modified palm oil (CPO) and enzymatically modified palm oil (EnPO) diets*

\begin{tabular}{lllllllll}
\hline & Lard & NPO & CPO & EnPO & Female & Male & $\begin{array}{l}\text { SEM } \\
\text { Diet }\end{array}$ & $\begin{array}{l}\text { SEM } \\
\text { Sex }\end{array}$ \\
\hline $12: 0$ & 0.07 & 0.07 & 0.11 & 0.08 & 0.11 & 0.07 & 0.07 & 0.04 \\
$14: 0$ & $1.53^{\mathrm{b}}$ & $1.10^{\mathrm{a}}$ & $1.06^{\mathrm{a}}$ & $1.23^{\mathrm{ab}}$ & 1.20 & 1.26 & 0.16 & 0.14 \\
$16: 0$ & $27.3^{\mathrm{b}}$ & $22.5^{\mathrm{a}}$ & $24.8^{\mathrm{ab}}$ & $26.5^{\mathrm{ab}}$ & 25.3 & 25.3 & 2.74 & 2.62 \\
$16: 1$ & 1.29 & 1.14 & 0.94 & 1.07 & 1.11 & 1.10 & 0.24 & 0.23 \\
$18: 0$ & $11.6^{\mathrm{b}}$ & $8.75^{\mathrm{a}}$ & $9.58^{\mathrm{ab}}$ & $9.98^{\mathrm{ab}}$ & 9.71 & 10.3 & 1.36 & 0.90 \\
$18: 1$ & $39.9^{\mathrm{a}}$ & $50.2^{\mathrm{b}}$ & $48.4^{\mathrm{ab}}$ & $44.5^{\mathrm{ab}}$ & 46.2 & 45.3 & 4.84 & 3.91 \\
$18: 2$ & 16.2 & 15.1 & 13.9 & 15.3 & 14.8 & 15.4 & 1.65 & 1.52 \\
$18: 3$ & 0.75 & 0.59 & 0.48 & 0.54 & 0.63 & 0.56 & 0.13 & 0.11 \\
Total & $41.4^{\mathrm{b}}$ & $32.7^{\mathrm{a}}$ & $35.9^{\mathrm{ab}}$ & $38.3^{\mathrm{ab}}$ & 36.8 & 37.3 & 3.30 & 2.47 \\
SFA & & & & & & & & \\
Total & $41.2^{\mathrm{a}}$ & $51.3^{\mathrm{b}}$ & $49.4^{\mathrm{ab}}$ & $45.6^{\mathrm{ab}}$ & 47.4 & 46.4 & 4.75 & 3.95 \\
MUFA & & & & & & & & \\
Total & 17.4 & 15.9 & 14.6 & 16.1 & 15.9 & 16.3 & 1.76 & 1.63 \\
PUFA & & & & & & & & \\
\hline Teans & & & & & & & &
\end{tabular}

${ }^{*}$ Means are average of 10 observations for treatments and 20 observations for sexes. Data presented as mean \pm SEM.

$a, b, c$ Means with different superscripts between dietary treatments differ significantly at $\mathrm{P}<0.05$.

Abbreviations: SFA, saturated fatty acids; MUFA, monounsaturated fatty acids; PUFA, polyunsaturated fatty acids. 
dietary means has focused almost exclusively on reducing intake of cholesterol and fat. Triglycerides are the compounds that help fat move through the bloodstream. People who have high levels of LDL-C and low levels HDL-C often have high TGs $[24,25]$. Elevated TG levels are increasingly associated with increased risk for heart disease $[25,26]$. The present data show that natural palm oil is beneficial compared to CPO or EnPO or lard in terms of lowering blood TGs that are associated with obesity and heart disease. After 12 weeks feeding lard or palm oil diets, the total cholesterol and LDL-C levels in blood did not change. Plasma LDL-C content and the ratio of LDL-C to HDL-C of pigs fed natural PO tended to be lower compared to all other diets (Table 3). Because of the younger age of experimental animals, blood cholesterol, LDL-C, HDL-C and insulin did not differ significantly.

The results showed a lower saturated fatty acid deposition in tissues of muscle (14:0 \& 18:0; P < 0.001; Table 4) and subcutaneous fat (14:0, 16:0, 18:0 \& SFA; $\mathrm{P}<0.05$; Table 5) with palm oil diet. This is consistent with our findings of a reduction in subcutaneous fat thickness with NPO diet compared to lard. The hydrolysis of the triglyceride components of chylomicrons and very low density lipoproteins in the circulatory systems is catalysed by lipoprotein lipase enzyme (LPL). The LPL enzyme is mainly located on the capillary surface within muscle and adipose tissues for hydrolysis of circulating lipoproteins, thereby providing free fatty acids and 2-monoglycerides for tissue utilisation i.e., either for the deposition of fatty acids in tissues or energy release through mitochondrial oxidation of free fatty acids. The lower saturated fat levels $(\mathrm{P}<0.05)$ in subcutaneous adipose tissue with NPO diet could be due to lower levels of circulating TG (Table 3) which may influence fatty acid deposition in the body. The lower saturated fat levels in subcutaneous adipose tissue with NPO had also resulted in a smaller $(\mathrm{P}<0.05)$ adipose tissue thickness (P2 fat) in those animals. This effect might have been due to a cumulative process of decrease in saturated fat deposition such as palmitic and stearic acids with natural palm oil feeding. Because the melting point of saturated fats is higher than monounsaturated fats, they provide structure and insulation to the external body through their firmness. The data on plasma TG, tissue fatty acids and back fat (subcutaneous) thickness indicates that natural palm oil may have beneficial effects on obesity through reduction in fatness in the body [27]. The reduction in saturated fats in the body needs further investigation. There was evidence of sex difference; females had higher saturated (14:0, 16:0) and monounsaturated $(16: 1,18: 1)$ fats in the muscles than males while the polyunsaturated $(18: 2 n-6)$ fat was higher in males than females. Adipose tissue fatty acid composition did not change between sexes.
The results also show that the significant reduction found in back fat depth with NPO diet was in line with the reduction in saturated fat content in adipose tissue (back fat depth), plasma LDL-C and TG levels. Since we have used younger pigs (weaners at 4 weeks age) in the study, the greater proportion of dietary energy would have been utilised for muscle and bone growth while the energy utilised for fat deposition would be expected to be lower. However, we hypothesised that consumption of all diets with high saturated fat in early life may not lead to the development of obesity and cardiovascular diseases later in life. The findings of this study support the suggestion that positional distribution of palmitic acid present in TG structure of palm oil confers a favourable plasma lipid profile and fat deposition in the body, which may prevent the development of obesity.

Together, these results suggest that feeding NPO to adult pigs may elicit even more healthful effects in terms of cholesterol synthesis and lipid metabolism. This is because, a greater proportion of the dietary metabolisable energy would be utilised for fat deposition as a result of decline in protein synthesis and bone growth with ageing or maturity, in adult humans/adult pigs. In pigs [28] and sheep [29] maintained under same feeding background, carcass fatness and leanness (muscle) obtained at different stages indicated that as the age increased, lean muscle content decreased and fat content increased in the body. In addition, application of diets with natural palm oil containing palmitic acid at different positions to meat producing animals may lead to the production of meat and meat products with lower saturated fats.

\section{Conclusions}

Natural PO diet significantly lowered the plasma TG content relative to the lard or EnPO diets, but was not different from the CPO diet. Plasma LDL-C content and the ratio of LDL-C to HDL-C in pigs fed NPO tended to be lower compared to all other diets. The lower saturated fat content in subcutaneous adipose tissue with NPO diet could be due to lower levels of circulatory TG that was observed in that group compared with lard diet. This effect appears to be related to palm oil's positional distribution of palmitic acid in the TG moiety. An increase in body fat content and a decrease in lean content in female pigs resulted an increased fat:lean ratio, but sex had no effect on blood lipid parameters or insulin concentration. In general, the lipid metabolism and the fat deposition in adult pigs are different from young pigs. This is because in young animals the metabolisable energy drawn from diet is mainly used for muscle/bone growth and development. In adult pigs, while the muscle accretion declines with age, the major portion of dietary 
energy is diverted to fat deposition. Feeding palm oil to adult pigs may provide more favourable outcomes in terms of lowering blood TG levels and fat deposition in the body. However, this needs to be investigated in adult pigs including the whole body composition analysis using dual energy X-ray absorptiometry (DXA).

\section{Acknowledgements}

The study was funded by the Malaysian Palm Oil Board, Kuala Lumpur, Malaysia. For the animal slaughter and sample collection, the excellent cooperation of Diamond Valley Pork, Victoria, abattoir employees and management is gratefully acknowledged. Technical support towards feeding, blood and tissue sample collection and laboratory analysis was provided by Matthew Kerr, Athula Naththarampatha and Maree Cox, DPI Victoria.

\section{Author details}

'AgriFood Production Systems, FFSR, Department of Primary Industries, 600 Sneydes Road, Werribee VIC 3030, Australia. ${ }^{2}$ Molecular Nutrition Unit, School of Medicine, Deakin University, Geelong VIC 3217, Australia. ${ }^{3}$ Malaysian Palm Oil Board, 43000 Kajang, Selangor, Malaysia. ${ }^{4}$ Melbourne School of Land and Environment, The University of Melbourne, Parkville, Vic. 3010, Australia.

\section{Authors' contributions}

ENP carried out the experimental study as a principle investigator and drafted the manuscript. PL carried out the analysis of blood for lipid metabolites and insulin concentrations, and participated in the interpretation of data. ENP, FRD, KN, and HG participated in the project proposal development, design of the study, the statistical analysis, and interpretation of data. Technical staff from the Department of Primary Industries conducted the tissue fatty acid analysis under ENP's supervision. All authors read and approved the final manuscript.

\section{Competing interests}

The authors declare that they have no competing interests.

Received: 11 January 2011 Accepted: 18 May 2011

Published: 18 May 2011

\section{References}

1. Dietz WH: The obesity epidemic in young children: Reduce television viewing and promote playing. William H Dietz BMJ 2001, 322:313.

2. Hakanen M, Lagström H, Kaitosaari T, Niinikoski H, Näntö-Salonen K, Jokinen E, Sillanmäki L, Viikari J, Rönnemaa T, Simell O: Development of overweight in an atherosclerosis prevention trial starting in early childhood. The STRIP study. Int J Obe 2006, 30:618-626.

3. Hu FB, Stampfer MJ, Manson JE, Ascherio A, Colditz GA, Speizer FE, Hennekens H, Willett WC: Dietary saturated fats and their food sources in relation to the risk of coronary heart disease in women. Am J Clin Nutr 1999, 70:1001-1008.

4. Murase T, Mizuno T, Omachi T, Onizawa K, Komine Y, Kondo H, Hase T, Tokimitsu I: Dietary diacylglycerol suppresses high fat and high sucrose diet-induced body fat accumulation in C57BL/6J mice. J Lipid Res 2001, 42:372-378.

5. Ashrafi K: Obesity and the regulation of fat metabolism. In The C elegans. Edited by: WormBook. Research Community, WormBook; 2007:[http://www. wormbook.org].

6. Pan DA, Lillioja S, Milner MR, Kriketos AD, Baur LA, Bogardus C, Storlien LH: Skeletal muscle membrane lipid composition is related to adiposity and insulin action. J Clin Invest 1995, 96:2802-2808.

7. Broughton $\mathrm{KS}$, Wade JW: Total fat and $(\mathrm{n}-3):(\mathrm{n}-6)$ fat ratios influence eicosanoid production in mice. J Nutr 2002, 132:88-94

8. Review IFIC: International Food Information Council Foundation. 2006 [http://www.foodinsight.org/Content/6/FIC\%20Brkfast\%20Review\%20FINAL pdf].

9. Mensink RP, Zock PL, Kester AD, Katan MB: Effects of dietary fatty acids and carbohydrates on the ratio of serum total to HDL cholesterol and on serum lipids and apolipoproteins: a meta-analysis of 60 controlled trials. Am J Clin Nutr 2003, 77:1146-1155.
10. Berry EM: Dietary fatty acids in the management of diabetes mellitus. American J Clin Nutr 1997, 66:991-997.

11. Grundy SM, Denke MA: Dietary influences on serum lipids and lipoproteins. J Lipid Res 1990, 31:1149-1172.

12. Katan MB, Zock PL, Mensink RP: Dietary oils, serum lipoproteins, and coronary heart disease. Am J Clin Nutr 1995, 61:1368-1373.

13. Innis $S$, Dyer $R$, Lien E: Formula containing randomized fats with palmitic acid (16:0) in the 2-position increases 16:0 in the 2-position of the plasma and chylomicron triglycerides in formula-fed piglets to levels approaching those of piglets fed sow's milk. J Nutr 1997, 127:1362-1370.

14. Berry SE: Triacylglycerol structure, interesterification and blood lipids. Nutr Res Rev 2009, 15:1-15.

15. Tierney AC, McMonagle J, Shaw DI, Gulseth HL, Helal O, Saris WH, Paniagua JA, Goł ąabek-Leszczyñska I, Defoort C, Williams CM, Karsltröm B, Vessby B, Dembinska-Kiec A, López-Miranda J, Blaak EE, Drevon CA, Gibney MJ, Lovegrove JA, Roche HM: Effects of dietary fat modification on insulin sensitivity and on other risk factors of the metabolic syndrome-LIPGENE: a European randomized dietary intervention study. Int J Obes (Lond) 2010.

16. Small DM: The effects of glyceride structure on absorption and metabolism. Annu Rev Nutr 1991, 11:413-434.

17. Costales-Rodríguez R, Gibon V, Verhé R, De Greyt W: Chemical and enzymatic interesterification of a blend of palm stearin: Soybean oil for low trans-margarine formulation. J Am Oil Chem Soc 2009, 86:681-697.

18. Suster D, Leury BJ, Hofmeyr CD, Dunshea FR: The accuracy of dual energy X-ray absorptiometry (DXA), weight and P2 back fat to predict halfcarcass and primal-cut composition in pigs within and across research experiments. Aust J Agric Res 2004, 55:973-982.

19. Ponnampalam EN, Hopkins DL, Butler KL, Dunshea FR, Warner RD: Genotype and age effects on sheep meat production 4. Carcass composition. Aust J Expt Agric 2007, 47:1172-1179.

20. Warnick GR, Knopp RH, Fitzpatrick V, Branson L: Estimating low-density lipoprotein cholesterol by the Friedewald equation is adequate for classifying patients on the basis of nationally recommended cutpoints. Clin Chem 1990, 36:15-19.

21. Ponnampalam EN, Mann NJ, Sinclair AJ: Effect of feeding systems on omega-3 fatty acids, conjugated linoleic acid and trans fatty acids in Australian beef cuts: potential impact on human health. Asia Pac J Clin Nutr 2006, 15:21-29.

22. Fanimo AO, Fashina-Bombata HA: The response of weaner pigs to diets containing palm oil slurry. Anim Feed Sci \& Tech 1998, 71:191-195.

23. Tsunenari T, Tsutsumi M, Ohno K, Yamamoto Y, Kawakatsu M, Shimogaki K, Negishi H, Sugimoto T, Fukase M, Fujita T: Age- and gender-related changes in body composition in Japanese subjects. J Bone \& Mineral Res 1993, 8:397-402.

24. Erkkilä AT, Sarkkinen ES, Lehto S, Pyörälä K, Uusitupa MI: Dietary associates of serum total, $\mathrm{LDL}$, and $\mathrm{HDL}$ cholesterol and triglycerides in patients with coronary heart disease. Prev Med 1999, 28:558-565.

25. Ballesteros ER, Mollejo M, Rodriguez A, Camacho Fl, Algara P, Martinez N, Pollán M, Sanchez-Aquilera A, Menarguez J, Campo E, Martinez P, Mateo M, Piris MA: Splenic marginal zone lymphoma: proposal of new diagnostic and prognostic markers identified after tissue and CDNA microarray analysis. Blood 2005, 106(5):1831-1838.

26. Chen J, Muntner P, Hamm LL, Jones DW, Batuman V, Fonseca V, Whelton PK, He J: The Metabolic Syndrome and Chronic Kidney Disease in U.S. Adults. Ann Intern Med 2004, 140:167-174.

27. Tsuji H, Kasai M, Takeuchi H, Nakamura M, Okazaki M, Kondo K: Dietary medium chain triacylglycerols suppress accumulation of body fat in a double-blind, controlled trial in healthy men and women. J Nutr 2001, 131:2853-59.

28. Suster D, Leury BJ, Kerton DJ, Borg MR, Butler KL, Dunshea FR: Longitudinal DXA measurements demonstrate lifetime differences in lean and fat tissue deposition in individually penned and group-penned boars and barrows. Aust J Agric Res 2006, 57:1009-1015.

29. Ponnampalam EN, Butler KL, Hopkins DL, Kerr MG, Dunshea FR, Warner RD: Genotype and age effects on sheep meat production 5. Aust J Expt Agric 2008, 48:893-897, Lean meat and fat content in the carcasses of Australian sheep genotypes at 20,30 and $40 \mathrm{~kg}$ carcass weights..

doi:10.1186/1475-2891-10-53

Cite this article as: Ponnampalam et al: Differential effects of natural palm oil, chemically- and enzymatically-modified palm oil on weight gain, blood lipid metabolites and fat deposition in a pediatric pig model. Nutrition Journal 2011 10:53. 